Blaxter, personal communication). This study confirms that the unemployed have higher rates of ill health using a wide range of both physical and mental health measures.

It is now widely accepted that the unemployed, and members of low social classes, have poorer health, but there is still controversy over how these health differences are generated and maintained. Dr Scott suggests that we should only "try to evaluate the extent of the known ... and accepted causes of ill health," such as bad housing, smoking, alcohol, diet, and exercise. The crucial research questions are not whether these factors cause ill health but the underlying reasons why people live in poor housing, abuse alcohol, smoke, have an inappropriate diet, or take too little exercise. In answering these questions the Health Education Council report The Health Divide ${ }^{3}$ discusses the ways in which all household resources-income, housing, fuel, food, and transport-have the potential to influence health. For example, it documents the large number of studies which show how low incomes, and particularly trying to live on existing benefit levels, lead to inadequate diets. The individual's living and working conditions have a determining influence on his or her personal behaviour, such as smoking, diet, exercise, and alcohol consumption.

The research challenge is not simply to conduct more surveys to document the correlates of poor health but to conduct more detailed and in depth studies which explicitly examine the mechanisms through which structural factors such as unemployment lead to disadvantaged environmental circumstances and to lifestyles or personal behaviour which is not health promoting. Health policy must be informed by research into what it is about the material and psychosocial experience of unemployment which leads to poor health.

SARA ARBER

Department of Sociology,

University of Surrey,

Guildford GU2 5XH

1 Cox BD. The health and lifestyle survey. London: Health Promotion Research Trust, 1987.

2 Whitehead M. The health divide: inequalities in health in the $1980 \mathrm{~s}$. London: Health Education Council, 1987.

\section{Screening for congenital dislocation of the hip}

SIR,-Dr Aidan MacFarlane (25 April, p 1047) rather understates the problem of screening for congenital dislocation of the hip. Paediatric orthopaedic surgeons are acutely aware of the need to avoid major surgery in infants with hip displacement. They are also aware of the possible overtreatment of neonates with unstable hips by rigid splintage, which carries its own morbidity as far as compressive vascular injury of the immature femoral head is concerned. Hence their interest in and their hope for ultrasound.

Ultrasound is clearly the answer to the diagnostic and management problems of neonates with hip instability. I have been using ultrasound since $1982,{ }^{1}$ and our recent prospective study in Coventry suggests that the 441 at risk neonates benefited from an ultrasound scan. Clinical normality does not necessarily indicate normal hip location, and regular ultrasound examinations can detect those displaced hips that will resolve spontaneously.

Dr MacFarlane asks why all those who are concerned with screening for congenital dislocation of the hip did not receive a copy of the new government handbook. One of the problems that we are faced with is the inadequacy of the clinical examination for congenital dislocation of the hip in multidisciplinary, inexperienced hands, although we accept that the experienced examiner will detect most cases. It is unfortunate, therefore, that the screening handbook was written just as ultrasound was being developed as a technique for infant hip examination. Many European countries are proceeding with a programme, and, in my view, any at risk infant in Britain should be examined with ultrasound.

We can no longer afford to ignore ultrasound in the diagnosis and management of congenital dislocation of the hip, and paediatricians and orthopaedic surgeons should make it their responsibility to ensure its availability.

N M P CLARKE

Bristol Royal Infirmary,

Bristol BS2 8HW

1 Clarke NMP, Harcke HT, McHugh P, Lee MS, Borns PF, Macewen GD. Real time ultrasound in the diagnosis of congenital dislocation and dysplasia of the hip. $\mathcal{J}$ Bone foint Surg (Br) 1985;67B:406-12.

\section{Screening for atlantoaxial instability}

SIR,-Dr Richard A Collacott's leading article (18 April, $p$ 988) adds to the case for routine screening for atlantoaxial instability in Down's syndrome. Such a programme would also alert us to the high incidence of degenerative disease of the cervical spine $^{1}$ and of cervical disc disease $e^{2}$ in this condition. Although the radiographic findings may not parallel pathological development, cervical neuropathy and myelopathy of degenerative skeletal origin might be more common among adults with Down's syndrome than is currently recognised. ${ }^{3}$

In 1986 my colleague Dr Martin White carried out radiographic screening of 21 men and 13 women with Down's syndrome who attended an adult training centre (average age 29 years, range 20-47). Two women showed atlantoaxial instability. Seven of the group had normal cervical spines but the striking finding was that 25 showed various combinations of degenerative arthritis of the cervical vertebrae and intervertebral discs. There were no neurological signs in the two cases of atlantoaxial instability, but five of the group with degenerative cervical arthritis showed clinical signs of myelopathy or neuropathy. Only one complained of symptoms related to the cervical spine, but people who suffer from mental handicap may have problems of communication. ${ }^{4}$

It is a reasonable recommendation that screening for atlantoaxial instability should be carried out at the age of 5-6 years. ${ }^{5}$ It is more important, however, that we continue to pay attention to the less dramatic but much more common changes which appear in early adult life in the cervical spines of those who suffer from Down's syndrome.

GWYN Howells

Gorseinon Hospital,
Swansea SA4 2UU

1 Martel W, Tishler JM. Observations on the spine in mongoloidism. American fournal of Roentgenology, Radium Therapy and Nuclear Medicine 1966;97:630-8.

Diamond LS, Lynne D, Sigman B. Orthopaedic disorders in patients with Down's syndrome. Orthop Clin North Am 1981;12:57-71.

3 Fidone GS. Degenerative cervical arthritis and Down's syndrome. $N$ Engl f Med 1986;314:320.

4 Howells $G$. Are the medical needs of mentally handicapped adults being met? $\mathcal{F} R$ Coll Gen Pract 1987;37:149-53.

5 Committee on sports medicine. Attantoaxial instability in Down's syndrome. Pediatrics 1984;74:152-4.

\section{RAWPing general practice}

SIR,-Professor Brian T Williams (2 May, p 1114) suggests that "non-financial considerations" deter dentists from reaping the "rich harvest" of "the unattended dental problems of the north."
Most dentists in general practice are well aware of the market forces that are increasingly being brought to bear on the profession. Advertising has been introduced by the government to promote competition between dentists, and National Health Service charges encourage many patients to seek basic and infrequent dental care: only those exempt from charges can avoid the average $70 \%$ contribution to the cost of their NHS dental treatment.

Though more patients are likely to be exempt from charges in the north than the south, the uneven distribution of dentists probably has more to do with the profession's perception of attitudes to dental treatment. Northerners have the reputation of being less interested in preserving their teeth than southerners. According to Primary Health Care: An Agenda for Discussion, however, the unevenness of the geographical distribution of dentists is reducing. The distribution of doctors is less uneven than that of dentists, and perhaps dental practices committees should be set up to "close" areas that have enough dentists if market forces do not have the desired effect. One of the London dental schools was closed recently, increasing the proportion of dentists trained in the north. Capitation experiments for children are under way, and this system may eventually provide the preventive dental care that is lacking under the present general dental service. Fluoridation on a national scale would also reduce geographical inequalities in dental caries.

All in all, it is a complex situation, in which education and "positive health" probably have as much, if not more, to offer than inducements.

I G CROSSMAN

Royal Alexandra Hospital for Sick Children,

Brighton BN1 3JN

\section{Effect of combined implants of oestradiol and testosterone on libido in postmenopausal women}

SIR, - Dr Henry Burger and colleagues conclude that testosterone is required to treat loss of libido effectively in postmenopausal women (11 April, p 936). While this is supported by some, though not all, related studies ${ }^{12}$ their own result may be questioned on three main points.

Firstly, how were patients kept blind to the nature of their treatment? It seems that they were offered a new implant because the first one failed. The authors themselves comment that the patients "chose to have a testosterone implant." Those who did not make this choice dropped out, so there was no comparison group in whom a delayed response to the first implant could have been observed. To have no comparison group in a self rating study whose subjects know the purpose of the study and the timing of new treatments creates methodological problems.

Secondly, estimating something as complex as libido by a self reported visual analogue scale is unsatisfactory, as is use of a three point scale to measure sexual enjoyment. We assess libido in postmenopausal women using the Golombok Rust inventory of sexual satisfaction, a 28 item questionnaire that provides an overall libido score and subscores for five components of sexual function.

Thirdly, the authors are correct to call their patients a highly selected group, all but one having had hysterectomy. There is evidence that psychological morbidity is prevalent in women attending menopause clinics and those who have undergone hysterectomies. ${ }^{34}$ Any decrease in anxiety or depression, whether a response to treatment, a placebo effect, or an unrelated change, might alter 